\title{
ANÁLISE DAS MANIFESTAÇÕES PATOLÓGICAS E CRIAÇÃO DO PLANO DE INSPEÇÃO NAS ESTRUTURAS DE CONCRETO ARMADO DA INDÚSTRIA PETROQUÍMICA
}

\author{
AMBROSI, ANDREW ARION DA ROSA \\ Engenheiro Civil \\ Universidade Feevale \\ Rio Grande do Sul; Brasil \\ andrewambrosi28@gmail.com
}

POLESELLO, EDUARDO

Engenheiro Civil, Prof. Dr.

Universidade Feevale

Rio Grande do Sul; Brasil

edupole@terra.com.br

\author{
THOEN, NICOLLAS ANDIGLIERI \\ Acadêmico de Engenharia Civil \\ Universidade Feevale \\ Rio Grande do Sul; Brasil \\ nicollasthoen@hotmail.com
}

\section{RESUMO}

Em unidades petroquímicas pode-se observar a existência de condições ambientais diversas e peculiares, nas estruturas de concreto armado, como presença de umidade constante e variações de temperatura, emissão de gases, presença de gelo, proteção contra fogo, vibrações excessivas, entre outras condições. Esses diferentes microclimas geram inúmeras possibilidades de manifestações patológicas às estruturas, devendo-se ter atenção especial às estruturas industriais. Este trabalho aborda as principais manifestações patológicas encontradas nas estruturas de concreto armado de unidades industriais petroquímicas, localizadas no Rio Grande do Sul. Com base nas análises de classes de agressividade ambientais, foi definido e implantado um plano de inspeção para as estruturas de concreto armado. Como consequência, garante-se um aumento da durabilidade e vida útil das estruturas de concreto nas unidades industriais.

Palavras-chave: petroquímicas. estruturas de concreto armado. agressividade ambiental. manifestações patológicas.

\begin{abstract}
In Petrochemical units may be observed by the existence of diverse and peculiar environmental conditions, in concrete structures, such as presence of constant humidity and temperature variations, emission of gases, presence of ice, fireproofing, excessive vibration, among other conditions. These different microclimates generate numerous possibilities for pathological manifestations of structures, with special attention to industrial structures. This work address the main pathological manifestations found in concrete structures of units in the South Petrochemical Complex. Based on the analyzes of environmental aggressiveness classes, it is intended to define and implement an inspection plan for concrete structures. As a result, it ensures an increase durability and service life of concrete structures in industrial units.
\end{abstract}

Keywords: petrochemicals. structures of reinforced concrete. environmental aggressiveness. pathological manifestations. 


\section{INTRODUÇÃO}

Para garantir um bom desempenho, a durabilidade e a vida útil das estruturas de concreto, são necessários cuidados especiais quanto à classificação de agressividade ambiental e análise das manifestações patológicas. Particularmente, destaca-se a importância da integridade das estruturas em indústrias petroquímicas, já que é possível identificar a existência de condições ambientais diversas e peculiares, apresentando diferentes microclimas dentro de uma mesma unidade, que, diferem do macroclima da região em que a unidade está inserida. As estruturas de concreto armado na indústria petroquímica são de suma importância para o processo produtivo, integridade das pessoas, das instalações e do meio ambiente. Em ambientes industriais, particularmente, ficam expostas a agentes agressivos e necessitam de cuidados especiais em suas fases de projeto, construção e operação para que atendam às expectativas de durabilidade. (CORSINI, 2013). Para Souza e Ripper (1998), as estruturas de concreto, quando estão em ambientes agressivos, podem sofrer deterioração pelos mais diversos fatores. Quando há falta de conhecimento, por parte do projetista, da localização da obra e das características do meio, como em zonas industriais que apresentam atmosferas agressivas, teores de umidade elevados, aliado ainda a falta de cuidados construtivos (como a camada de cobrimento insuficiente das armaduras, ausência de especificações ou especificações incorretas dos materiais a serem utilizados), podem essas falhas, individualmente ou em conjunto, criar as condições necessárias para reduzir o tempo de vida útil das estruturas, mostrando a necessidade de operações rotineiras de manutenção do concreto para manter as condições de projeto das estruturas da indústria petroquímica.

Segundo Cooling Tower Institute (2007), uma das estruturas presentes na indústria petroquímica são as torres de resfriamento, definidas como equipamentos de transferência de calor e massa, voltados para grandes demandas de resfriamento de água. As torres de resfriamento sofrem degradações e estão sujeitas aos mais variados agentes agressores, tais como: diferencial de temperatura, ação mecânica da queda da água nas paredes de concreto e águas agressivas. Dessa forma, as torres de resfriamento podem ser consideradas uma obra hidráulica, com algumas diferenças das estruturas comuns, devendo esta estrutura possuir características especiais, como boa qualidade do concreto armado, boa proteção das armaduras e boa resistência à impermeabilidade, para que apresente boa durabilidade. (SAMPAIO, 2013). Destaca-se, ainda, as bacias de contenção que, de acordo com a NBR 17505-1 (ABNT, 2006), tratam-se áreas que se constituem por uma depressão, pelo relevo do terreno ou ainda pode serem limitadas por um dique, possuindo a principal função de conter vazamentos de produtos. A parte 2 da NBR 17505 (ABNT, 2006), ainda especifica que a bacia de contenção deve estar adjacente a no mínimo duas vias diferentes.

Outro aspecto são os combustíveis e inflamáveis presentes nos processos petroquímicos que, segundo a norma americana API 2218 (AMERICAN PETROLEUM INSTITUTE, 1999), podem expor as estruturas muito rapidamente às temperaturas elevadas em caso de fogo, demandando adequada proteção para as estruturas. A função principal do revestimento de proteção contra fogo é proteger durante a fase inicial do incêndio, onde os esforços estão sendo concentrados para parar as unidades, isolar o processo e combater o incêndio. Durante este período crítico, o revestimento protegerá e dará um tempo adicional às estruturas antes do colapso.

Panossian (2013 apud PEDROSO, 2013, p.3), observa que "[...] toda estrutura de concreto armado, seja qual for o ambiente, está suscetível à deterioração, entretanto, quanto mais forte a agressividade ambiental do meio, mais veloz e intenso pode ser esse processo". Para Corsini (2013, p. 2) "Além da interação com o meio, outros fatores que interferem na maior ou menor deterioração são a qualidade do concreto executado, a espessura de cobrimento da armadura e a frequência e eficiência de intervenções de manutenção". De acordo com Mehta e Monteiro (2014), as causas de deterioração do concreto podem ser divididas em causas físicas e causas químicas.

As causas físicas de deterioração do concreto por desgastes superficiais, como abrasão, erosão e cavitação; e por fissuração, com mudanças de volume, carregamentos estruturais e exposição às variações extremas de temperatura, já para as causas químicas registram que "[...] as reações químicas envolvem interações químicas entre as intempéries do ambiente agressivo exposto e os constituintes da pasta de cimento". Os autores apontam as causas químicas de deterioração do concreto, por deterioração por sais, deterioração por ataque de sulfatos, deterioração por reações álcalisagregado, deterioração por corrosão do aço de armadura do concreto, deterioração por corrosão do aço de armadura do concreto (MEHTA e MONTEIRO, 2014, p. 161). Souza e Ripper (1998), registram ainda as ações biológicas, que podem atuar em todos os tipos de edificações e obras especiais, destacando-se como principal agente causador da deterioração do concreto o crescimento de vegetação, em que as raízes penetram nas fissuras e acabam desenvolvendo organismos e microorganismos, modificando o comportamento das estruturas. 
De acordo com a NBR 6118 (ABNT, 2014, p. 16), “[...] a agressividade está relacionada diretamente às ações físicas e químicas atuantes sobre as estruturas de concreto, na qual independem das ações mecânicas, variações volumétricas de origem térmica e retração hidráulica". O ambiente industrial possui classes de agressividade diversas, propiciando a degradação das estruturas de concreto, que devido aos processos associados e à natureza dos mesmos, os fatores de degradação são inúmeros (SILVA, 2011).

Mendonça e Danni-Oliveira (2007) definem que a climatologia é o estudo do clima que trata do comportamento da atmosfera interagindo com as atividades humanas e a superfície do planeta. As escalas climáticas são divididas quanto à dimensão, ou ordem de grandeza, sendo elas espaciais (em função da extensão) e temporais (em função do tempo), na qual os fenômenos climáticos são estudados. As classes de agressividade ambiental variam de acordo com o clima em que a estrutura está localizada, impactando diretamente na durabilidade das mesmas. Vários autores fazem definições de durabilidade e vida útil. Para Souza e Ripper (1998, p. 19), “[...] a associação de durabilidade e vida útil é necessária, pois se devem conhecer as características de deterioração do concreto, relacionando-as com os efeitos de agressividade ambiental, definindo assim a vida útil da estrutura". Mehta e Monteiro (2014, p. 125, 126) registram que "[...] mesmo concretos dosados, lançados e curados adequadamente, podem sofrer deterioração prematura das estruturas, reduzindo a sua durabilidade". Portanto, um concreto pode ser dito durável quando preservar sua forma, qualidade e capacidade de usos originais quando exposto ao ambiente de uso para o qual foi projetado.

Para garantir a durabilidade, manutenções e inspeções rotineiras se mostram essenciais ao longo da vida útil das estruturas. As atividades de inspeção têm por objetivo manter a operação contínua e segura das instalações, através da utilização de recursos humanos capacitados e tecnologia adequada para assegurar a integridade física dos equipamentos e estruturas (BRASKEM, 2007). Genericamente, a metodologia para a inspeção em estruturas contempla três etapas básicas: levantamento dos dados, análise e diagnóstico (SOUZA; RIPPER, 1998). Os relatórios de inspeção devem detalhar os serviços efetuados, as condições físicas e outros mecanismos de degradação encontrados durante a inspeção (BRASKEM, 2007). Na Engenharia Civil, a manutenção pode ser entendida como um conjunto de medidas necessárias e indispensáveis para garantir o bom estado de funcionamento, conservação e segurança dos elementos e instalações de uma edificação. Essas medidas, de qualquer forma ou grandeza, resultam em um conjunto de ações preventivas e corretivas, que tem a finalidade de preservar as edificações para que cumpram com as funções para as quais foram projetadas, de forma a garantir suas vidas úteis (MARCELLI, 2007).

Segundo a norma americana API 581 (AMERICAN PETROLEUM INSTITUTE, 2008), a inspeção baseada em risco (Risk Based Inspection- RBI) tem como princípio a quantificação das consequências de uma falha estrutural que cause algum dano ou ruptura. Com estes parâmetros é possível criar uma matriz do tipo "Probabilidades por Consequência" de cada estrutura, determinando o risco que eles representam. A partir da criação dos riscos associados à estrutura é possível determinar planos de inspeção, permitindo criar prazos de inspeção associados ao risco em cada unidade industrial.

A escolha por este tema justifica-se devido às unidades industriais possuírem inúmeros fatores que contribuem para acelerar as manifestações patológicas e degradações nas estruturas de concreto armado. Sendo assim, a relevância em definir e implantar um plano de inspeção para essas estruturas, com base nas classes de agressividade e em avaliações visuais, é extremamente importante. Um plano, se bem elaborado, torna-se uma ferramenta eficaz, reduzindo as manutenções corretivas e aumentando as manutenções preventivas em função das recomendações geradas pelas inspeções periódicas. Como consequência, as unidades industriais apresentarão estruturas de concreto armado com maior durabilidade e vida útil. Neste contexto, o objetivo desta pesquisa está direcionado para a análise das manifestações patológicas, através de avaliações visuais in loco, e criação de um plano de inspeção em estruturas de concreto armado de unidades industriais de petroquímicas, localizadas no estado do Rio Grande do Sul.

\section{METODOLOGIA}

Essa pesquisa foi estruturada, primeiramente, com uma revisão bibliográfica detalhada e, na sequência, foi feita a verificação e classificação ambiental das estruturas de acordo com o projeto, com a finalidade de levantar dados, como métodos construtivos e agentes agressores, a fim de zonear as estruturas de acordo com as diferentes classes de agressividade para o concreto em decorrência dos diferentes microclimas encontrados. Avaliações visuais das estruturas foram realizadas, a fim de identificar e mapear as possíveis causas das manifestações patológicas. Com base nas análises de classes de agressividade ambientais e nas avaliações visuais realizadas, definiu-se e implantou-se um plano de inspeção através da metodologia de inspeção baseada em risco, definida pela norma 581 do Instituto Americano de Petróleo (AMERICAN PETROLEUM INSTITUTE, API, 2008), para as estruturas de concreto armado; onde consta em cada estrutura, seu respectivo código de cores de acordo com sua classe de agressividade correspondente, seu intervalo 
máximo entre inspeções, sua área aproximada construída, sua identificação, área constituinte, tipo de estrutura, idade da estrutura, tipo de inspeção e ensaios realizados, manifestações patológicas encontradas, grau de urgência de reparo e anexo fotográfico dos principais pontos de deteriorações.

Deste modo, pretende-se fazer com que esse plano de manutenção se torne uma ferramenta eficaz na redução das manutenções corretivas e contribua na conscientização da necessidade de mais manutenções preventivas. As etapas seguidas por este estudo estão apresentadas na Figura 1.

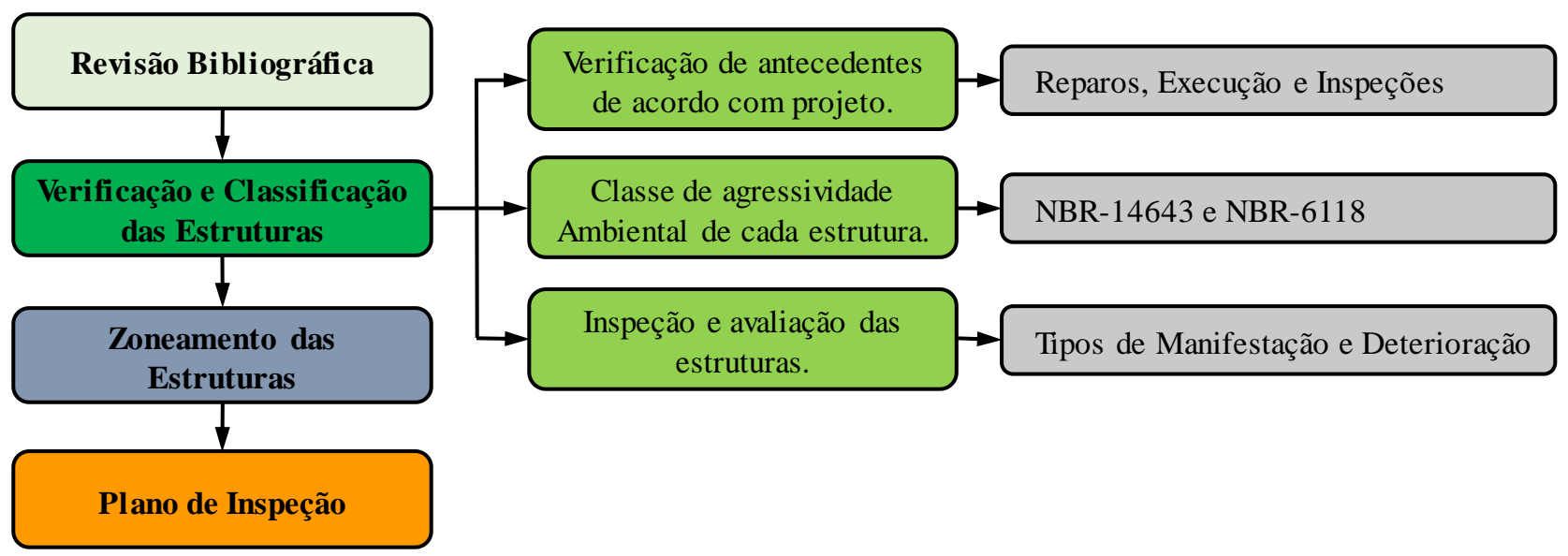

Figura 1 - Etapas seguidas no desenvolvimento da pesquisa

Cada etapa mostrou-se essencial, e se complementaram, para os resultados serem assertivos e consistentes. A revisão bibliográfica embasou teoricamente as análises. Na etapa de verificação e classificação das estruturas, registrou-se as informações e dados de projeto, foi especificada a classificação dos microclimas existentes em cada estrutura e realizouse uma inspeção in loco para todas as estruturas. Com isso, foi possível fazer o zoneamento das estruturas de concreto armado, estabelecendo para cada estrutura, segundo um código de cores, uma classificação de acordo com sua classe de agressividade correspondente. O Quadro 1 apresenta a compilação das classificações de normas e o microclima local em que cada estrutura está inserida.

Quadro 1 - Zoneamento das estruturas segundo NBR 14643 (ABNT, 2001) e NBR 6118 (ABNT, 2014)

\begin{tabular}{|c|c|c|l|}
\hline SETOR & NBR 14643 & NBR 6118 & \multicolumn{1}{|c|}{ MICROCLIMA INSERIDO } \\
\hline AZUL & $\mathrm{C} 2$ & Classe II & Microclima pouco agressivo. \\
\hline VERDE & $\mathrm{C} 3$ & Classe II & $\begin{array}{l}\text { Microclima medianamente úmido com tempo de condensação de 3\% a 30\% e/ou presença de } \\
\mathrm{SO}_{2} \text { (dióxido de enxofre) entre } 12 \text { e 40 } \mu \mathrm{g} / \mathrm{m} \text {; sem emanação de gases ou ácidos } \\
\text { localizadamente; todos os fatores dentro da média do macro clima. }\end{array}$ \\
\hline AMARELO & $\mathrm{C} 4$ & Classe III & $\begin{array}{l}\text { Microclima úmido com tempo de condensação de 30\% a 60\% e/ou presença de } \mathrm{SO}_{2} \text { (dióxido de } \\
\text { enxofre) entre 40 e } 90 \mu \mathrm{g} / \mathrm{m} \text {; emanação de gases ou ácidos localizadamente, não muito intensa, } \\
\text { porém superior à média. }\end{array}$ \\
\hline PERMELHO & $\mathrm{C} 5$ & Classe IV & $\begin{array}{l}\text { Microclima muito úmido com tempo de condensação superior a 60\% e/ou presença de } \mathrm{SO}_{2} \\
\text { (dióxido de enxofre) entre } 90 \text { e 250 } \mu \mathrm{g} / \mathrm{m} \text {; emanação de gases ou ácidos localizadamente. }\end{array}$ \\
\hline C6 & Classe IV & $\begin{array}{l}\text { Microclima extremamente úmido com tempo de condensação próximo a 100\% e/ou presença } \\
\text { de } \mathrm{SO}_{2} \text { (dióxido de enxofre) acima de } 250 \mu \mathrm{g} / \mathrm{m} \text {; emanação de gases ou ácidos localizadamente. }\end{array}$ \\
\hline
\end{tabular}

Fonte: Elaborado pelos autores (2019)

A última etapa constitui-se na criação do plano de inspeção para as estruturas de concreto armado. A partir das etapas anteriores e da compilação dos dados levantados, definiu-se o intervalo máximo permitido entre as inspeções das estruturas de concreto localizadas em cada zona, pelo seu código de cores, conforme especificações apresentadas no Quadro 2. Para a criação do plano de inspeção, com seus respectivos prazos, foi utilizada a metodologia de inspeção baseada em risco (RBI), através de uma matriz de risco. 
Quadro 2 - Definição do intervalo máximo de inspeções em função da classe de agressividade ambiental (CAA)

\begin{tabular}{|c|c|}
\hline Classe de Agressividade Ambiental & Intervalo Máximo entre Inspeções \\
\hline C3 - VERDE & 5 anos \\
\hline C4 - AMARELO & 3 anos \\
\hline C5 - VERMELHO & 2 anos \\
\hline C6 - PRETO & 1 ano \\
\hline
\end{tabular}

Fonte: Elaborado pelos autores (2019)

\section{RESULTADOS E ANÁLISES}

Conforme detalhado na metodologia, todas as estruturas de concreto armado das unidades industriais de uma indústria petroquímica localizada no estado do Rio Grande do Sul, totalizando cinquenta e cinco estruturas e $43.628 \mathrm{~m}^{2}$ de obras, foram inspecionadas, analisadas, classificadas por zonas de agressividade para posterior criação do plano de inspeção. Deste total foram criadas quatro zonas específicas de condições de microclima em toda a unidade industrial, diferenciadas por um código de cores, conforme detalhado na Figura 2.

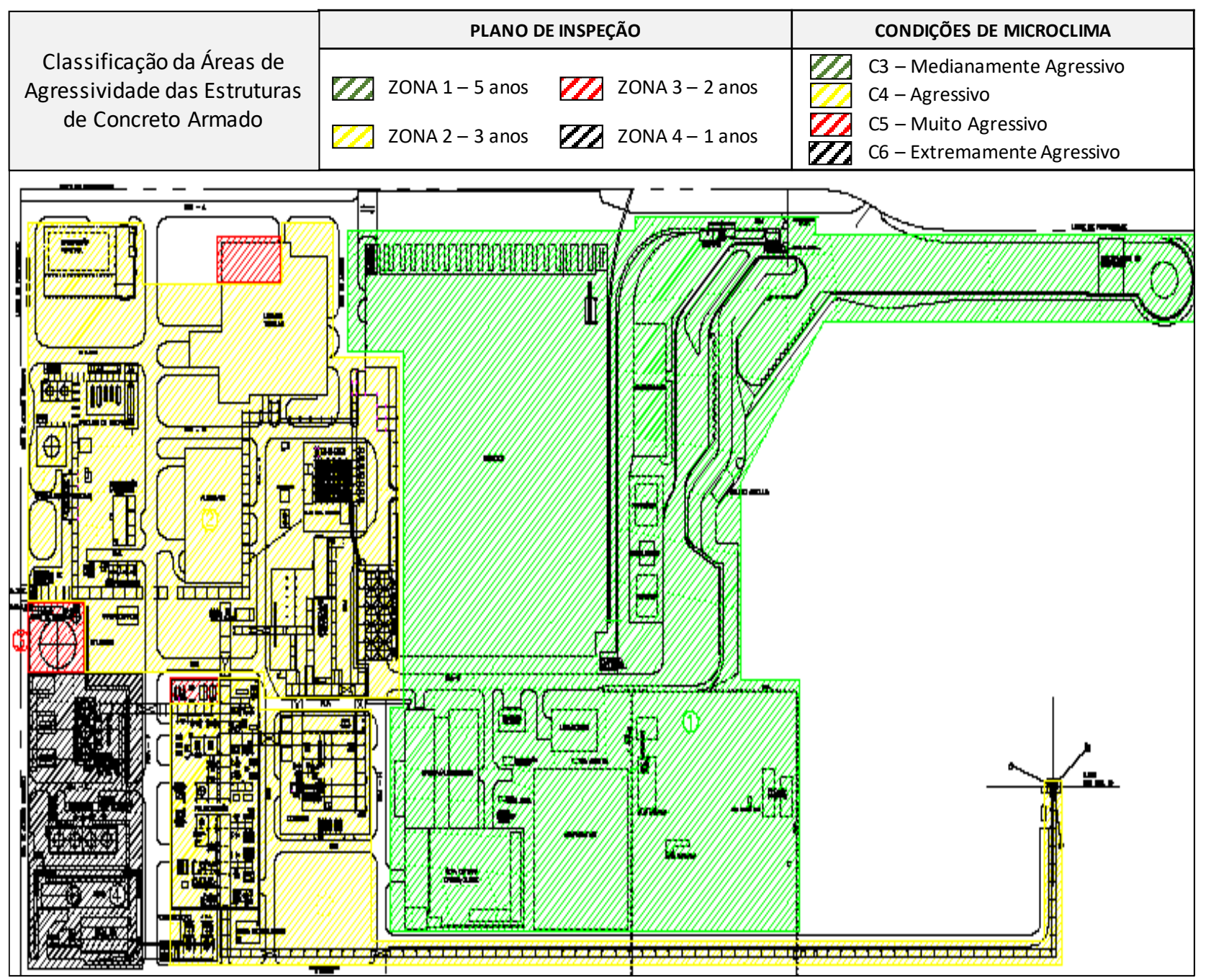

Figura 2 - Esquema da planta industrial com os códigos de cores em função da agressividade ambiental

Esse código de cores está diretamente associado à região onde a estrutura está inserida e às condições de microclima que a mesma está exposta durante sua vida útil. Cabe salientar que, para a planta estudada, em nenhuma parte identificou-se uma zona classificada com condições de microclima pouco agressivo. 
Para melhor compreensão dos resultados obtidos através dos dados coletados, foram criadas tabelas independentes de cada estrutura de concreto armado, nas quais consta o levantamento de várias informações relevantes para o correto diagnóstico. Desta forma, cada estrutura foi analisada e enquadrada dentro de uma zona do programa de inspeções. Os Quadros 3, 4, 5 e 6 exemplificam a elaboração e execução deste plano de inspeção para, respectivamente, Zonas 1, 2, 3 e 4 .

Quadro 3 - Exemplo de inspeção em estrutura na ZONA 1

\begin{tabular}{|c|c|c|}
\hline \multicolumn{3}{|c|}{ ZONA 1} \\
\hline Condições de Microclima & MEDIANAMENTE AGRESSIVO - C3 & \multirow{2}{*}{$\begin{array}{l}\text { FOTOS GERAIS DA } \\
\text { ESTRUTURA }\end{array}$} \\
\hline Áreas Constituintes & Prédio Balança & \\
\hline Numeração das Áreas & $*$ & \\
\hline Idade da Es trutura & 36 anos & \\
\hline Tipo de Estrutura & Vigas/Pilares e Alvenaria Convencional. & \\
\hline Área Aproximada Construída & $75 \mathrm{~m}^{2}$ & \\
\hline Tempo de Inspeção Estimado & 1 hora & \\
\hline Intervalo Máximo entre Inspeções & 5 anos & \\
\hline Tipo de Inspeção e Ensaio & $\begin{array}{l}\text { Inspeção visual, comparador de fissuras, verificação de } \\
\text { antecedentes e percursão com martelo. }\end{array}$ & \\
\hline $\begin{array}{l}\text { Resumo das Manifestações } \\
\text { Patológicas Encontradas }\end{array}$ & $\begin{array}{l}\text { Umidade ascendente nas regiões inferiores das alvenarias, pelo } \\
\text { lado externo e interno da estrutura e umidade descendnete na } \\
\text { laje superior, desplacamento e empolamento da pintura e } \\
\text { fissuras de até } 3 \mathrm{~mm} \text { de latgura nas paredes Oeste. Fissura } 45^{\circ} \\
\text { abaixo da janela lado Oeste, fissuras de até } 5 \mathrm{~mm} \text {. }\end{array}$ & \\
\hline $\begin{array}{r}\text { Ensaios Necessários para Análise } \\
\text { Detalhada }\end{array}$ & $\begin{array}{l}\text { Limpeza das alvenarias e remoção dos revestimentos } \\
\text { degradados. }\end{array}$ & \\
\hline Grau de Urgência do Reparo & Baixo. & \\
\hline
\end{tabular}

Fonte: Elaborado pelos autores (2019)

Quadro 4 - Exemplo de inspeção em estrutura na ZONA 2

\begin{tabular}{|c|c|c|}
\hline \multicolumn{3}{|c|}{ ZONA 2} \\
\hline Condições de Microclima & AGRESSIVO - C4 & \multirow{2}{*}{$\begin{array}{l}\text { FOTOS GERAIS DA } \\
\text { ESTRUTURA }\end{array}$} \\
\hline Áreas Constituintes & Pilares e Vigas Silos Unidade 1 e 2 & \\
\hline Numeração das Áreas & Área & \\
\hline Idade da Estrutura & 36 anos & \\
\hline Tipo de Estrutura & Sistema vigas/pilares de concreto armado & \\
\hline Área Aproximada Construída & $1213 \mathrm{~m}^{2}$ & \\
\hline Tempo de Inspeção Estimado & 4 horas & \\
\hline Intervalo Máximo entre Inspeções & 3 anos & \\
\hline Tipo de Inspeção e Ensaio & $\begin{array}{l}\text { Inspeção visual, comparador de fissuras, verificação de } \\
\text { antecedentes e percursão com martelo. }\end{array}$ & \\
\hline $\begin{array}{l}\text { Resumo das Manifestações } \\
\text { Patológicas Encontradas }\end{array}$ & $\begin{array}{l}\text { Fissuras verticais de até } 60 \mathrm{~mm} \text { de abertura e desplacamento no } \\
\text { concreto com armaduras expostas e já com perda de seção em } \\
7 \text { dos pilares lado Norte. }\end{array}$ & \\
\hline $\begin{array}{r}\text { Ensaios Necessários para Análise } \\
\text { Detalhada }\end{array}$ & $\begin{array}{l}\text { Remoção do concreto degradado para avaliação da seção da } \\
\text { armadura. }\end{array}$ & \\
\hline Grau de Urgência do Reparo & Alto. & \\
\hline
\end{tabular}

Fonte: Elaborado pelos autores (2019) 
Quadro 5 - Exemplo de inspeção em estrutura na ZONA 3

\begin{tabular}{|c|c|c|}
\hline \multicolumn{3}{|c|}{ ZONA 3} \\
\hline Condições de Microclima & MUITO AGRESSIVO - C5 & \multirow{12}{*}{$\begin{array}{l}\text { FOTOS GERAIS DA } \\
\text { ESTRUTURA }\end{array}$} \\
\hline Áreas Constituintes & Área Fria Unidade 3 & \\
\hline Numeração das Áreas & Área 700 & \\
\hline Idade da Estrutura & 22 anos & \\
\hline Tipo de Estrutura & Radier de concreto armado & \\
\hline Área Aproximada Construída & $270 \mathrm{~m}^{2}$ & \\
\hline Tempo de Inspeção Estimado & 2 horas & \\
\hline Intervalo Máximo entre Inspeções & 2 anos & \\
\hline Tipo de Inspeção e Ensaio & $\begin{array}{l}\text { Inspeção visual, verificação de antecedentes e percursão com } \\
\text { martelo. }\end{array}$ & \\
\hline $\begin{array}{l}\text { Resumo das Manifestações } \\
\text { Patológicas Encontradas }\end{array}$ & Em boas condições visuais. & \\
\hline $\begin{array}{r}\text { Ensaios Necessários para Análise } \\
\text { Detalhada }\end{array}$ & Nenhum. & \\
\hline Grau de Urgência do Reparo & Nenhum. & \\
\hline
\end{tabular}

Fonte: Elaborado pelos autores (2019)

Quadro 6 - Exemplo de inspeção em estrutura na ZONA 4

\begin{tabular}{|c|c|c|}
\hline \multicolumn{2}{|r|}{ EXTREMAMENTE AGRESSIVO - C6 } & \multirow{2}{*}{$\begin{array}{l}\text { FOTOS GERAIS DA } \\
\text { ESTRUTURA }\end{array}$} \\
\hline Áreas Constituintes & Torre de resfriamento Unidades 1 e 2 & \\
\hline Numeração das Áreas & E-310A1/A2/A3/A4 & \\
\hline Idade da Es trutura & 36 anos & \\
\hline Tipo de Estrutura & Vigas/Pilares e blocos pré-moldados. & \\
\hline Área Aproximada Construída & $500 \mathrm{~m}^{2}$ & \\
\hline Tempo de Inspe ção Estimado & 3 horas & \\
\hline Intervalo Máximo entre Inspeções & 1 ano & \\
\hline Tipo de Inspeção e Ensaio & $\begin{array}{l}\text { Inspeção visual, comparador de fissuras, verificação de } \\
\text { antecedentes e percursão com martelo. }\end{array}$ & \\
\hline $\begin{array}{l}\text { Resumo das Manifestações } \\
\text { Patológicas Encontradas }\end{array}$ & $\begin{array}{l}\text { Fissuras verticais nos blocos pré-moldados de concreto de até } \\
6 \mathrm{~mm} \text { de abertura, com sinais de carbonatação e eflorescência. } \\
\text { Difusores com desplacamento e lasqueamento do concreto } \\
\text { com armaduras expostas e sinais de carbonatação. Regiões do } \\
\text { concreto aparente, apresentando presença de ação biológica. }\end{array}$ & \\
\hline $\begin{array}{r}\text { Ensaios Necessários para Análise } \\
\text { Detalhada }\end{array}$ & $\begin{array}{l}\text { Ensaios de carbontação eeflorescência. Remoção do concreto } \\
\text { degradado e medição da seção da armadura. Efetuar limpeza } \\
\text { da Torre de Resfriamento. }\end{array}$ & \\
\hline Grau de Urgência do Reparo & Alto. & \\
\hline
\end{tabular}

Fonte: Elaborado pelos autores (2019)

De acordo com os dados obtidos nas inspeções e avaliações in loco das cinquenta e cinco estruturas, correspondente às quatro zonas avaliadas, foi possível elaborar uma análise global dos resultados. Desse total de estruturas inspecionadas observou-se que, aproximadamente, em $61 \%$ das estruturas algum tipo de manifestação patológica foi verificado. A 
Figura 3 apresenta as informações coletadas de todas as manifestações patológicas encontradas, expressando, percentualmente, o número de estruturas com a presença de cada uma dessas manifestações.

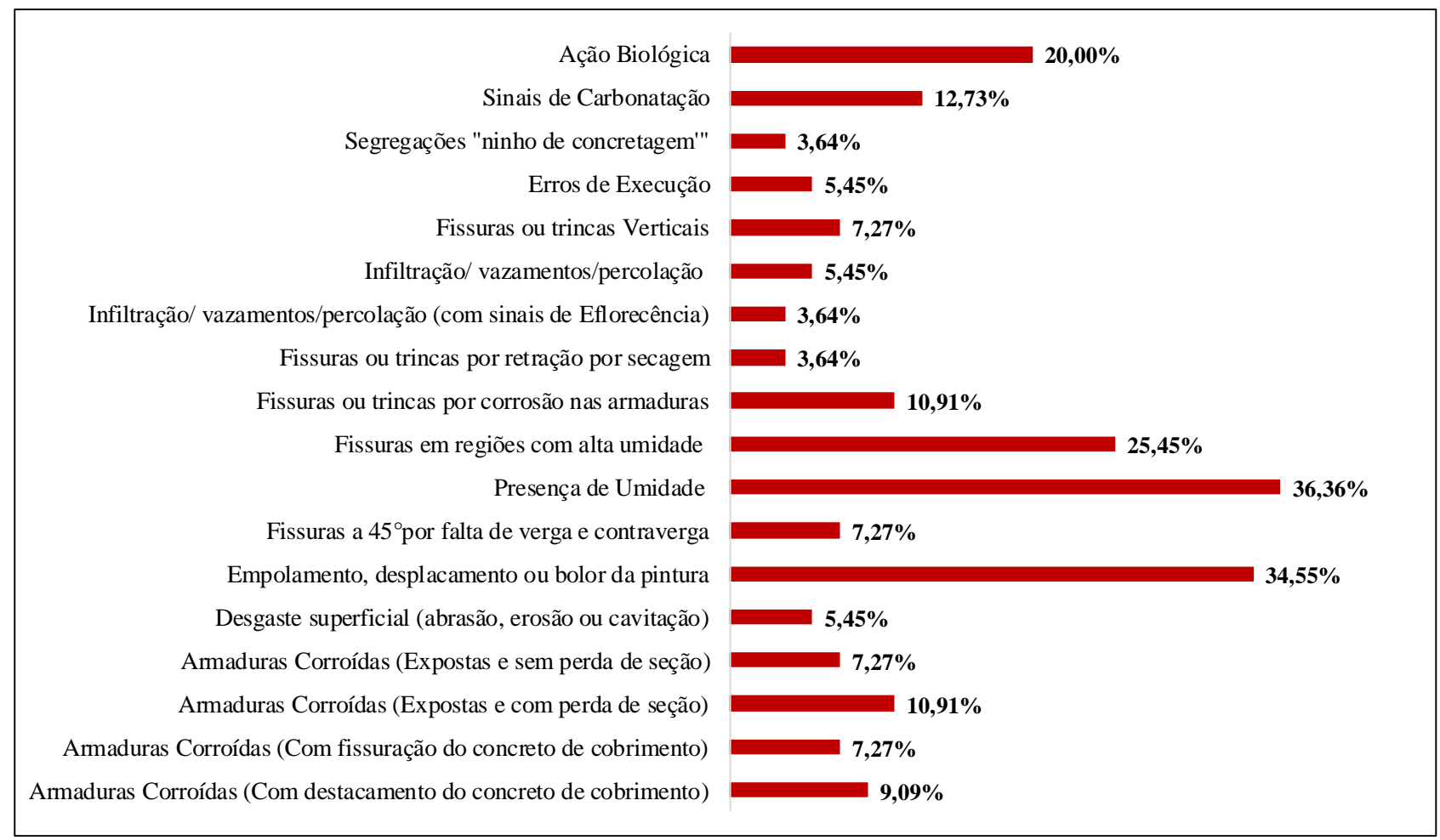

Figura 3 - Incidência de estruturas com manifestações patológicas avaliando todas as zonas da planta industrial

Em uma análise global o problema de umidade se destacou, sendo registrado em 36,36\% das estruturas e, como consequência, registrou-se também danos na pintura, fissuras nos revestimentos e presença de ação biológica (fungos e manchas). Para Guzmán (2011), os gradientes de umidade são grandes causadores de variações volumétricas no concreto, gerando assim fissuras, devido à retração dos agregados, ciclos de umedecimento e secagem, e a retração hidráulica.

Sinais de carbonatação foram evidenciados em $12,73 \%$ das estruturas, demandando ensaios complementares para identificar a real evidência deste tipo de manifestação patológica. A carbonatação é um fenômeno que ocorre devido às interações entre componentes presentes no concreto e no meio ambiente em que está inserido. A NBR 6118 (ABNT, 2014), para reduzir os impactos da carbonatação recomenda-se observar a espessura do cobrimento a ser adotada em projeto, a abertura de fissuras dos elementos e a utilização de concreto com porosidade reduzida.

Em 10,91\% das estruturas foram evidenciadas armaduras corroídas já expostas e com perda de seção e 7,27\% sem perda de seção. Como consequência deste tipo de manifestação patológica, visualizou-se desplacamento e fissuras do concreto de cobrimento encontrados, respectivamente, em 9,09\% e 7,27\% nos locais onde haviam armaduras corroídas. De acordo com Souza e Ripper (1998), a formação da corrosão no aço gera uma variação volumétrica que produz tensões no concreto, podendo fissurá-lo e desplacar a camada de cobrimento existente, sendo que o principal problema gerado por este mecanismo é a perda da seção de aço existente.

Registrou-se, também, que em $7,27 \%$ das estruturas foram evidenciadas fissuras a $45^{\circ}$ por falta de vergas ou contravergas nas esquadrias dos prédios industriais, e em 3,64\% das estruturas foi evidenciada segregações na base de pilares robustos de sustentação dos silos da unidade 3. Os vazios, ou ninhos de concretagem, relacionados a erros de execução, afetam a durabilidade e resistência das estruturas de concreto, que poderão sofrer deformações ou até mesmo entrar em colapso. As manifestações patológicas devido a erros de execução ou supervisão inadequada foram identificadas em 5,45\% das estruturas. De acordo com Cremonini (1988), para não haver problemas de manifestações patológicas posteriores à execução, deve-se ter o controle dos materiais utilizados e utilizar mão de obra especializada, assim como, atentar e fiscalizar se a construção está de acordo com as especificações no projeto. 
Em 3,64\% das estruturas de concreto foram evidenciadas fissuras ou trincas verticais, como consequência, registrou-se infiltração e vazamentos com sinais de eflorescência também em 3,64\% das estruturas. Infiltração e vazamentos, porém sem sinais de eflorescência apareceram em 5,45\% das estruturas. Em 5,45\% das estruturas foi evidenciado desgaste superficial de lajes expostas a intempéries. Para Mehta e Monteiro (2014), quando um fluido contendo partículas sólidas suspensas entra em contato com o concreto, a colisão ou deslize dessas partículas causam um desgaste superficial.

Vale salientar que em vinte e uma das estruturas, ou seja, 39\% do total inspecionado, não foram evidenciados sinais de manifestações patológicas ou degradações visuais, em sua maioria devido à execução de manutenções corretivas, ao longo dos últimos anos. A comparação realizada objetivou o fornecimento de informações para a correlação entre as quatro zonas das unidades industriais, a fim de identificar em porcentagem as inúmeras manifestações patológicas encontradas e confrontar com a falta de manutenção preventiva existentes nessas unidades industriais.

\section{CONCLUSÕES}

Este trabalho teve o principal objetivo de criar um plano de inspeção para todas as estruturas de concreto armado da unidade industrial de uma petroquímica, localizada no estado do Rio Grande do Sul. Somente foi gerada a criação desse plano de inspeção utilizando-se a metodologia de inspeção baseada em risco. Através desta metodologia foi possível avaliar e quantificar o risco associado a cada estrutura de concreto armado na unidade industrial, criando assim prazos consistentes e cabíveis para a inspeção periódica dessas estruturas.

Observa-se através dos resultados obtidos, que foi identificado um elevado número de manifestações patológicas, em sua maioria devido à alta taxa de agressividade e, em paralelo, à falta de manutenções preventivas executadas. Exposto isto, ficou evidente o elevado percentual de degradações relacionado à umidade e, como consequência, o aparecimento de outros tipos de danos. Foram identificados vários outros danos, entretanto os problemas que envolvem fissuras ou trincas por corrosão nas armaduras apresentam níveis críticos de deterioração, necessitando intervenção imediata, pois, além da notória capacidade de resistência diminuída, no contexto da durabilidade, essas anomalias constituem-se no caminho mais rápido de penetração dos agentes agressivos até a armadura, contribuindo para a rápida diminuição da vida útil dos elementos estruturais e risco à integridade das pessoas.

Com as recomendações geradas a partir das inspeções e avaliações executadas, compiladas com o plano de inspeção criado, pretende-se que as manutenções corretivas aconteçam nas estruturas já danificadas e as manutenções preventivas sejam constantemente executadas, a fim de focar na durabilidade da estrutura. Sendo assim, este trabalho serve de referência a engenheiros, construtores, projetistas e líderes empresariais, mostrando a real necessidade do devido cuidado com a execução e acompanhamento de estruturas de concreto armado, além da execução de manutenções preventivas rotineiras, garantindo assim o bom estado, funcionamento, conservação e segurança dos elementos estruturais.

Aos trabalhos futuros referentes ao tema, sugere-se a complementação da pesquisa, com realização de ensaios, a fim de confirmação de algumas manifestações patológicas, como carbonatação e eflorescência. Além da criação de um plano paralelo ao de inspeção, com periodicidades de limpeza em todas as estruturas que apresentaram algum tipo de degradação ocasionada pela umidade, com o intuito de manter os níveis de limpeza e umidade sempre dentro do esperado para uma indústria petroquímica.

\section{REFERÊNCIAS}

AMERICAN PETROLEUM INSTITUTE. Fireproofing practices in petroleum and petrochemical processing plant. $2^{\text {nd }}$ ed., Washington: API Publication 2218, 1999.

AMERICAN PETROLEUM INSTITUTE. Risk-based inspection. $2^{\text {nd }} e d .$, Washington: API Publication 581, 2008.

ASSOCIAÇÃO BRASILEIRA DE NORMAS TÉCNICAS. NBR 6118. Projeto e Execução de Obras de Concreto Armado. Rio de Janeiro: 2014.

NBR 14643. Corrosão Atmosférica: Classificação da corrosividade de atmosfera, 2001.

NBR 17505-1. Armazenagem de líquidos inflamáveis e combustíveis. Parte 1: Armazenagem em tanques estacionários, 2006. 
vasos, 2006.

NBR 17505-2. Armazenagem de líquidos inflamáveis e combustíveis. Parte 2: Armazenagem em tanques e

BRASKEM. Manual de Gerenciamento da Manutenção. Triunfo: 2007.

COOLING TOWER INSTITUTE (CTI). Apresenta recursos e atividades desenvolvidas. Houston.Disponível em: <http://www.cti.org >. Acesso em: $1^{\circ}$ maio 2018.

CORSINI, Rodnei. Ambientes agressivos. RevistaTéchne, 196, jul. 2013.

CREMONINI, Ruy Alberto. Incidência de manifestações patológicas em unidades escolares da região de Porto Alegre: Recomendações para projeto, execução e manutenção. Universidade Federal do Rio Grande do Sul, Porto Alegre, RS, 1988. Disponível em: < https://lume.ufrgs.br/handle/10183/1420>. Acesso em: 15 abr. 2018.

GUZMÁN, D. S. DE. Durabilidad y patología del concreto. 2a. ed. Bogotá: A socreto, 2011.

MARCELLI, Maurício. Sinistros na construção civil: causas e soluções para danos e prejuízos em obras. São Paulo: Pini, 2007.

MEHTA, P. Kumar; MONTEIRO, Paulo J.M. Concreto: microestrutura, propriedades e materiais. 2. ed. São Paulo:NicolePaganHasparyk, 2014.

MENDONÇA, Francisco; DANNI-OLIVEIRA, Inês Moresco. Climatologia: noções básicas e climas do Brasil. São Paulo: Oficina de Textos, 2009.

PEDROSO,FábioLuís.Concreto: as origens e a evolução do material construtivo mais usado pelo homem. Revista Concreto e Construções, Ano XXXVII, nº 53, jan.-mar. 2009.

SAMPAIO, Franco Serighelli. Torre de resfriamento: modelagem, simulação e testes experimentais para apoio ao ensino de Engenharia Mecânica. 2013. 171f. (Monografia) - Faculdade de Engenharia Mecânica, Universidade de Brasília, Brasília, 2013.

SILVA,LuizaKilvia da. Levantamento de manifestações patológicas em estruturas de concreto armado no estado do Ceará. 2011. 61f. (Monografia), Faculdade de Engenharia Civil - Universidade Federal do Ceará, Fortaleza,2011.

SOUZA, Vicente Custódio de Moreira; RIPPER, Thomaz.Patologia, recuperação e reforço de estruturas de concreto.São Paulo: Pini, 1998. 